\title{
CONTRATOS PÚBLICOS DE EMERGENCIA Y CRISIS DEL COVID-19: INMEDIATEZ CONTRA SEGURIDAD JURÍDICA
}

\author{
EMERGENCY PUBLIC CONTRACTS AND COVID-19 \\ CRISIS: IMMEDIACY AGAINST LEGAL CERTAINTY
}

\begin{tabular}{|c|c|}
\hline \multicolumn{2}{|c|}{ ARTÍCULO INÉDITO DE INVESTIGACIÓN } \\
\hline CÓMO CITAR ESTE ARTÍCULO (CHICAGO) & 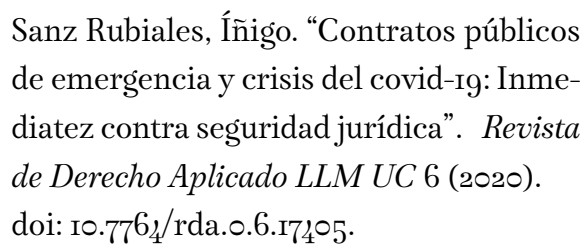 \\
\hline REVISTA DE DERECHO APLICADO LLM UC & $\begin{array}{l}\text { Número } 6 \\
\text { Diciembre } 2020 \\
\text { ISSN: } 245^{2-4344}\end{array}$ \\
\hline & $\begin{array}{l}\text { Recepción: I5 de julio, } 2020 \\
\text { Aceptación: Io de agosto, } 2020\end{array}$ \\
\hline
\end{tabular}




\section{Resumen}

La ley española de contratos incluye una regulación de la contratación pública en casos de emergencia que elimina controles para facilitar la inmediatez de la prestación, y que puede ser complementada por las normas específicas dictadas para situaciones excepcionales, como ha ocurrido con la crisis del covid-19, que adapta la regulación de emergencia a las necesidades de provisión de bienes y servicios sobrevenidas con la pandemia. Se mantienen en cualquier caso diversos controles imprescindibles, ya sean previos, como la justificación causal, porque la Administración no es libre tampoco cuando contrata; o posteriores, como la publicidad de la adjudicación y los controles judiciales.

Palabras clave: Contratos públicos, emergencia, procedimiento administrativo, covid-19, transparencia, competencia.

\section{Abstract}

The Spanish Contract Law includes a regulation of public procurement in cases of emergency, which eliminates controls to facilitate the immediacy of the provision, and which can be complemented by the specific regulations issued for exceptional situations, as has happened with the Covid-19 crisis, that adapts the emergency regulations to the needs for the provision of goods and services that have arisen with the pandemic. In any case, various essential controls are maintained, either prior, such as causal justification, because the Administration is not free either when concluding contracts, or later, such as the publicity of the award and judicial controls.

Keywords: Public contracts, emergency, administrative procedure, Covid-19, transparency, competition. 


\section{Íñigo Sanz Rubiales}

Universidad de Valladolid

Valladolid, España

inigo.sanz@uva.es

Universidad de Valladolid

Valladolid, Spain

inigo.sanz@uva.es
Iñigo Sanz Rubiales es catedrático de Derecho Administrativo en la Universidad de Valladolid, España.

Iñigo Sanz Rubiales is Professor of Administrative Law at the University of Valladolid, Spain. 


\section{INTRODUCCIÓN}

La pandemia del covid-19 ha puesto a prueba algunas de las más importantes instituciones del derecho administrativo. Entre ellas destacan, sin duda, las vinculadas al estado de necesidad ${ }^{1}$.

En situaciones de necesidad, la normativa de derecho público prevé las necesarias modificaciones procedimentales, competenciales u organizativas, de forma que, frente a situaciones excepcionales, la Administración pueda responder de forma inmediata y adecuada. Los procedimientos de formación de la voluntad administrativa ordinarios son sustituidos por decisiones inmediatas; las competencias de órganos colegiados o representativos con frecuencia pasan a órganos unipersonales; se habilita de forma genérica la adopción de medidas para responder a las necesidades inaplazables. Podría decirse que lo importante no es ya tanto la legalidad formal y la salvaguarda de los derechos procedimentales de los ciudadanos, cuanto la satisfacción inmediata de necesidades de provisión de bienes y servicios y de construcción de obras públicas. La emergencia, la inmediatez, prima sobre todo lo demás. El problema que subyace en esta regulación contractual es, así, satisfacer las necesidades prestacionales sin perder las garantías esenciales de la legalidad.

En el ámbito contractual, la regulación de la situación de necesidad se plasma en la previsión de la contratación de emergencia, que elimina trámites procedimentales y permite a la Administración contratar de forma casi inmediata para satisfacer las necesidades más imperiosas.

\section{LA PREVISIÓN DE LA LEY DE CONTRATOS DEL SECTOR PÚBLICO: UNA REGULACIÓN APTA PARA TODAS LAS EMERGENCIAS}

Siguiendo una previsión ya tradicional ${ }^{2}$, la Ley 9/2017, del 8 de noviembre, de Contratos del Sector Público, contiene una regulación mínima de tramitación de los contratos públicos en casos de emergencia. Esta regulación pretende eliminar los obstáculos que pueden impedir o dificultar la inmediata dación de bienes o prestación de servicios.

A estos efectos, la Ley incluye diversas precisiones sobre la regulación de la contratación en situaciones de emergencia, susceptibles de ser complementadas por normas ad hoc,

1 Es imprescindible, en esta materia, la conocida monografía de Vicente Álvarez García, El concepto de necesidad en derecho público (Madrid: Civitas, I996), passim.

2 Véanse, sobre la contratación de emergencia, los artículos 25.3 y 27 de la Ley de Contratos del Estado de $\mathrm{I}_{96}{ }_{5}$ (Decreto $923 / \mathrm{I}_{96}$, del 8 de abril, por el que se aprueba el texto articulado de la Ley de Contratos del Estado), y el artículo 73 de la Ley I3/1995, del I8 de mayo, de Contratos de las Administraciones Públicas, que derogó la anterior. 
pero que constituyen el marco general de la contratación pública en este tipo de situaciones. Destaca la previsión del art. 120, con carácter general.

\section{I. La tramitación de emergencia (artículo I20)}

\section{I.I. Alcance}

El artículo 120 de la Ley 9/2017 lleva por título "Tramitación de emergencia". Por su ubicación sistemática ${ }^{3}$, hace referencia a la tramitación del expediente de preparación de los contratos públicos, anterior a la fase de adjudicación. Es decir, alude al expediente de contratación, dirigido a concretar la voluntad administrativa (el objeto del contrato), previo a la selección de contratistas (que constituye la segunda parte del procedimiento de contratación, regulado como sección segunda, tras la preparación, que es la sección primera).

Por lo tanto, en teoría, la tramitación de emergencia no afecta ni a la segunda parte de la fase in fieri (selección de contratistas y adjudicación del contrato) ni a la ejecución (fase in facto esse $)^{4}$.

Sin embargo, en la medida en que la aprobación del expediente de contratación implica la aprobación de los pliegos de cláusulas administrativas - y técnicas-, será determinante del procedimiento de adjudicación y de los criterios de adjudicación que deben utilizarse en la segunda parte del procedimiento administrativo. No solo eso: es absurdo que en una situación de extrema urgencia o de emergencia, se suprima el procedimiento de determinación de la voluntad contractual administrativa, pero se mantenga el procedimiento de adjudicación, habida cuenta de que hay "procedimientos" de selección de contratistas recogidos en la Ley que se caracterizan, precisamente, por la falta de procedimiento (como la adjudicación directa).

3 Se encuentra en el libro segundo ("De los contratos de las Administraciones Públicas"), título I ("Disposiciones generales"), capítulo r ("De las actuaciones relativas a la contratación de las Administraciones Públicas") y se incluye en la sección primera ("De la preparación de los contratos de las Administraciones Públicas"), subsección primera ("Expediente de contratación”), tras la regulación general (artículos Iı6-II7) de los contratos menores (artículo II8) y de la tramitación urgente (artículo irg).

4 Esta terminología, muy gráfica, puede encontrarse en numerosas aportaciones de la doctrina de derecho canónico referida al matrimonio - de hecho, el Diccionario panhispánico del español jurídico de la Real Academia Española lo aplica al contrato matrimonial-, pero, en la actualidad, se puede encontrar en estudios de algunos administrativistas, aplicada a la estructura de la contratación pública y administrativa: por todos, José Luis Martínez López-Muñiz, "Naturaleza de los contratos públicos a la luz del derecho español, su fundamento y sus consecuencias", en Derecho administrativo: Obra colectiva en homenaje al profesor Miguel S. Marienhoff, coord. por Juan Carlos Cassagne (Buenos Aires: Abeledo-Perrot, I998), $95^{\circ}$ y ss. 
Por eso, en los casos de emergencia, el procedimiento de selección de contratistas debe ajustarse a la emergencia: el único de los procedimientos establecidos en la Ley, a estos efectos, es el negociado sin publicidad, como se deduce de la ley española y del propio derecho comunitario ${ }^{5}$. No en vano, la Comisión Europea recuerda que, en el contrato negociado sin publicidad, "en la práctica, [...] las autoridades pueden actuar con toda la rapidez que sea técnica y físicamente posible, y el procedimiento puede constituir una adjudicación directa de facto sujeta únicamente a limitaciones físicas o técnicas relacionadas con la disponibilidad real y la velocidad de entrega"

\section{I.2. El supuesto de hecho}

El supuesto de hecho para la contratación de emergencia está planteado mediante conceptos jurídicos indeterminados, que permiten acoger supuestos imprevisibles en el momento de la redacción de la Ley, tanto situaciones catastróficas o relacionadas con la defensa nacional, como situaciones de "grave peligro". Al no especificar el tipo de peligro, tienen cabida situaciones tan dispares como la crisis de los controladores aéreos de 2010 covid-19 de 2020 u otras situaciones catastróficas de alcance local (inundaciones, incendios, terremotos, etcétera).

No precisa declaración alguna de esta situación, a diferencia del supuesto de hecho de la tramitación urgente del expediente (artículo 119.1 de la Ley 9/2017), porque se basa en la notoriedad de la situación excepcional, que hace innecesaria esa declaración.

La característica común a sendos supuestos es que, una vez que se producen, exigen la "actuación inmediata" de la Administración, para la cual esta precisa proveerse de bienes o servicios, que serán objeto de contratación, en su caso.

\section{I.3. Habilitación: Tres posibilidades de reacción frente al supuesto de hecho}

Como establece el artículo 120.1 de la Ley 9/2017, "el órgano de contratación, sin obligación de tramitar expediente de contratación, podrá ordenar la ejecución de lo necesario para remediar el acontecimiento producido o satisfacer la necesidad sobrevenida, o contratar libremente su objeto".

5 Artículo r68 letra b) de la Ley 9/20I7 y artículo 32.2 letra c) de la Directiva 20I4/24, del 26 de febrero, que apuntan a las razones de imperiosa urgencia como justificadoras de la aplicación de contratos negociados sin publicidad.

6 Comisión Europea, "Orientaciones de la Comisión Europea sobre el uso del marco de contratación pública en la situación de emergencia relacionada con la crisis del covid-r9”, Diario Oficial de la Unión Europea, 2020/C I08 I/or, I de abril de 2020, https://eur-lex.europa.eu/legal-content/ES/TXT/PDF/?uri=CELEX:52020XCo, ${ }_{4}$ ( $\left(0_{5}\right) \&$ from=EN.

7 Real Decreto I673/20ı, del 4 de diciembre, por el que se declara el estado de alarma para la normalización del servicio público esencial del transporte aéreo. 
Es decir, el órgano de contratación puede acudir a la ejecución administrativa de la prestación - es una excepción a la contratación pública, artículo 30.1 letra d) de la Ley 9/2017), puede acudir a contratación in house o por medios propios (artículo 32) o puede "contratar libremente" sin sujetarse a requisitos formales o previa existencia de crédito.

Ambas técnicas - la ejecución directa administrativa o a través de medios propios personificados-son excepcionales, o deben serlo, porque vienen a restringir la concurrencia de las empresas privadas ${ }^{8}$. No hay que olvidar que lo más propio de la Administración es mandar, mientras que la gestión empresarial es más propiamente privada, propia de los particulares - como reconoce la Constitución en el artículo 38: "Se reconoce la libertad de empresa en el marco de la economía de mercado. Los poderes públicos garantizan y protegen su ejercicio"- . De ahí que la Ley 9/2017 imponga fuertes restricciones a esa utilización de medios propios - con o sin personificación-; también lo hacen las directivas europeas de contratos, al referirse a la utilización de medios propios.

Por eso, la razón de la existencia actual de estos medios propios - personificados o no-de titularidad administrativa es la urgencia o emergencia de actuaciones, que por la vía de la contratación sensu stricto no podrían llevarse a cabo con la misma celeridad. Es decir, están justificadas estas técnicas en los casos de emergencia.

\section{I.4. El problema de la contratación "libre": Las limitaciones a los contratos de emergencia}

Según el citado artículo 120.1 de la Ley 9/2017, el órgano de contratación, "sin obligación de tramitar expediente de contratación", puede "contratar libremente su objeto, en todo o en parte, sin sujetarse a los requisitos formales establecidos en la presente Ley, incluso el de la existencia de crédito suficiente" (el destacado es nuestro). Esta previsión normativa debe interpretarse de manera adecuada, a la vista de la condición administrativa del sujeto contratante, para evitar consecuencias que puedan distorsionar la naturaleza de la contratación pública.

La Administración no es libre. No lo es cuando ejerce potestades restrictivas de derechos y no lo es tampoco cuando contrata. La Administración, como sabemos, está vinculada de manera positiva a la ley (artículo 103.1 de la Constitución española), también cuando celebra contratos. La regla de la autonomía de la voluntad, recogida por el Código Civil,

8 José Luis Martínez López-Muñiz, “¿Sociedades públicas para construir y contratar obras públicas?”, Revista de Administración Pública I44 (1997): 45-74. 
no es aplicable a la Administración ${ }^{9}$. La Administración no puede contratar cómo y con quien quiera sin necesidad de justificación.

Frente a las libertades de los ciudadanos, que se caracterizan - entre otras cosas - por la no necesidad de justificación de su ejercicio, el Estado no es libre nunca, ni siquiera cuando utiliza la contratación de emergencia. Como señala la nota informativa de la Junta Consultiva de Contratación Pública del Estado (JCCPE) de abril de 2020 sobre los contratos públicos en la situación del covid-19, la Administración no es enteramente libre para contratar porque "está sometida a la concurrencia de una causa legal que la justifique"10.

En concreto, el órgano de contratación necesita una causa contractual ${ }^{11}$ y justificar con carácter previo al procedimiento administrativo de preparación del contrato la necesidad de contratar (motivación). Como señala el artículo 28 de la Ley 9/2017 ("Necesidad e idoneidad del contrato y eficiencia en la contratación”):

Las entidades del sector público no podrán celebrar otros contratos que aquellos que sean necesarios para el cumplimiento y realización de sus fines institucionales. A tal efecto, la naturaleza y extensión de las necesidades que pretenden cubrirse mediante el contrato proyectado, así como la idoneidad de su objeto y contenido para satisfacerlas, cuando se adjudique por un procedimiento abierto, restringido o negociado sin publicidad, deben ser determinadas con precisión, dejando constancia de ello en la documentación preparatoria, antes de iniciar el procedimiento encaminado a su adjudicación.

9 Aunque la doctrina administrativista, siguiendo la letra de la ley, habla de "libertad de pactos" de las Administraciones públicas (artículo 34 de la Ley 9/20I7) — por todos, Juan Alfonso Santamaría Pastor, Principios de derecho administrativo II, $5 \cdot{ }^{\text {a }}$ ed. (Madrid: Iustel, 20I8), 202-, lo cierto es que la Administración carece de la autonomía de la voluntad propia de los sujetos privados, característica de la vinculación negativa al ordenamiento y plasmada en el artículo I.255 del Código Civil: "Los contratantes pueden establecer los pactos, cláusulas y condiciones que tengan por conveniente, siempre que no sean contrarios a las leyes, a la moral ni al orden público".

10 Nota informativa de la Junta Consultiva de Contratación Pública del Estado, abril de 2020, https://www.hacienda.gob.es/Documentacion/Publico/D.G.\%2०PATRIMONIO/Junta\%2oConsultiva/Notas/NOTA\%20EMERGENCIA\%20COVID-r9\%20F.pdf.

11 De acuerdo con la doctrina civilista, caben dos concepciones de la causa: como la contraprestación de la otra parte y como fin. Destaca esta en los contratos públicos, que deben satisfacer un fin de interés general. Cfr., sobre el interés general como causa en los contratos públicos, Víctor Sebastián Baca Oneto, La invalidez de los contratos públicos (Madrid: Thomson Reuters Civitas, 2006), 234 y ss. 
Pero, además, la inexistencia de contratación libre se aprecia en que la Administración está sometida al principio de interpretación restrictiva de la contratación informal, de acuerdo con el principio de proporcionalidad ${ }^{12}$.

De hecho, el artículo 120.2 establece dicho criterio, que solo permite eludir el procedimiento contractual para las prestaciones de emergencia, de tal forma que "las restantes prestaciones que sean necesarias para completar la actuación acometida por la Administración y que no tengan carácter de emergencia se contratarán con arreglo a la tramitación ordinaria regulada en esta Ley".

En la misma línea, la Comisión Europea señala que la contratación sin procedimiento pautado solo puede usarse "en la medida estrictamente necesaria para cubrir el vacío hasta que se encuentren soluciones más estables"13.

Asimismo, la citada nota informativa de la JCCPE establece, entre otras condiciones, la necesidad de cumplir lo dispuesto en la Disposición Adicional 136 de la Ley 6/2018, del 3 de julio, de Presupuestos Generales del Estado para el año 2018, que alude a la comunicación del inicio de actuaciones mediante régimen de tramitación de emergencia a la intervención delegada cuya competencia orgánica o territorial se corresponda con la de la autoridad que haya de aprobar el gasto necesario para hacer frente a dicha actuación. Esta comunicación tendrá lugar en el mismo momento de adoptar el acuerdo de inicio de actuaciones precisas. En la comunicación que se remita al órgano de control correspondiente, se incluirá una descripción del objeto de las actuaciones a ejecutar y el importe del gasto por el que se haya efectuado la oportuna retención de crédito o se vaya a iniciar el expediente de modificación presupuestaria.

Por último, otras limitaciones - esta vez, a posteriori-de los contratos adoptados bajo el amparo del artículo 120 son, por una parte, la obligación de los órganos de contratación del sector público estatal de rendir cuenta al Consejo de Ministros en el plazo de treinta días desde el contrato (artículo 120.1 letra b); por otra, la ejecución inmediata (en menos de un mes) (artículo 120.1 letra c) y, de forma destacada, la publicación de la adjudicación. Aunque no cabe ni el anuncio de la convocatoria del contrato ni su control en vía de re-

12 En esta línea, Isabel Gallego Córcoles, "Los procedimientos abiertos, restringido, licitación con negociación, negociado sin publicidad y diálogo competitivo". En Estudio sistemático de la ley de contratos del sector público, dir. por José María Gimeno Feliú (Madrid: Aranzadi, 2018) y José María Gimeno Feliú, "La crisis sanitaria covid-rg y su incidencia en la contratación pública”, El Cronista del Estado Social y Democrático de Derecho 86-87 (2020): 44 y ss.

13 Comisión Europea, "Orientaciones...”. 
curso especial, sí que es perfectamente exigible la publicación de la adjudicación (artículo 154.1 de la Ley 9/2017) ${ }^{14}$, como reconoce también la Comisión Europea.

\subsection{Otras facilidades para la contratación emergente}

Además de las facilidades configuradas por el artículo 120, otros preceptos de la misma Ley benefician este tipo de contratación a efectos de facilitar la citada inmediatez. Por una parte, el artículo 44.4 exime el procedimiento de adjudicación de contratos en situaciones de emergencia del recurso administrativo especial que resuelven los Tribunales de Recursos Contractuales, lo que supone que en ningún caso el contrato puede verse suspendido por esa vía, que conlleva la suspensión automática de la adjudicación (artículo 53.1) ${ }^{15}$; por otra parte, el artículo 37.1, que prohíbe la contratación pública verbal, admite como única excepción la contratación de emergencia, lo cual no significa ni mucho menos que necesariamente tenga que ser verbal dicha contratación, pero sí que solo puede darse, por su carácter excepcional, en situaciones de emergencia. También se facilita la subcontratación, en la medida en que en vez de exigir la acreditación de la aptitud del subcontratista con carácter previo a la celebración del contrato inter privatos, la Ley 9/2017, en su artículo 215.2 letra b), permite que se pueda acreditar después, una vez celebrado.

\subsection{Inaplicabilidad práctica de la contratación estratégica}

La regulación de la contratación de emergencia en la Ley 9/2017 se construye no solo sobre las disposiciones legales, sino también sobre sus omisiones. Estas disposiciones no hacen en ningún momento alusión a la contratación estratégica, que constituye una de las novedades claves de la regulación.

A la luz de la razón de ser de la contratación emergente y de la reducción de controles previos, parece evidente que la contratación estratégica no es exigible por obligación, como lo es en condiciones normales: como es sabido, las cláusulas ambientales pueden incluirse tanto a título de criterios de adjudicación como a título de condiciones de ejecución o de cláusulas técnicas ${ }^{16}$. Pues bien, por una parte, las condiciones de adjudicación no existen si no hay concurrencia; por otra, las cláusulas técnicas o las condiciones de ejecución de

14 En este mismo sentido, véase Eduardo Gamero Casado, "Transparencia y contratación de emergencia ante el covid-ı", Observatorio de Contratación Pública, ı6 de abril de 2020, http:// www.obcp.es/opiniones/transparencia-y-contratacion-de-emergencia-ante-el-covid-ig.

15 "Una vez interpuesto el recurso quedará en suspenso la tramitación del procedimiento cuando el acto recurrido sea el de adjudicación”.

16 Cfr. Ínigo Sanz Rubiales, "La protección del ambiente en la nueva Ley de Contratos: Del Estado meramente 'comprador' al Estado 'ordenador”, Revista de Administración Pública 205 (2018), 53 . 
carácter estratégico solo tienen cabida si no afectan en forma negativa a la inmediatez de la prestación. De hecho, los privilegios que se otorgan al órgano de contratación en la contratación "emergente" no se justifican si las especificidades técnicas estratégicas - por tanto, no necesarias para la prestación inmediata-complicasen o retrasasen la provisión de bienes o servicios contratada.

\section{LA ESPECÍFICA REGULACIÓN DE LOS CONTRATOS DE EMERGENCIA EN LA ETAPA COVID-I9}

En la medida en que las situaciones que justifican la contratación de emergencia pueden ser variadas, y a la vista de la genérica regulación de la Ley 9/2017, el Gobierno, mediante normas ad hoc, puede establecer regulaciones excepcionales que modifiquen dicha regulación.

Es lo que ha hecho el Gobierno de España mediante varios decretos leyes dictados durante la declaración de alarma, que han venido a facilitar la ya factible contratación de emergencia en el escenario específico del covid-19. Se trata de normas excepcionales, con vocación de provisionalidad, que modifican o complementan la normativa básica de la Ley a los solos efectos de la contratación con motivo de la pandemia.

Estas peculiaridades responden a una flexibilización aún mayor de la contratación emergente, en función de las específicas necesidades, apreciadas tras los primeros días del estado de alarma, del aprovisionamiento de determinados productos. Hay que pensar que se dictan en unos momentos de falta de aprovisionamiento de tests de detección de covid-19, mascarillas y respiradores; es decir, se aplican fundamentalmente a contratos de suministro. Por tanto, reducen aún más las garantías típicas de derecho público en favor de una agilización de la contratación.

¿Qué novedades introducen los reales decretos leyes respecto de la contratación emergente regulada por la Ley 9/2017?

\section{I. La presunción legal para la aplicación del artículo I20}

La primera previsión a la que hay que aludir está incluida en el artículo 16 del real Decreto Ley 7/2020, del 12 de marzo, que establece

la adopción de cualquier tipo de medida directa o indirecta por parte de las entidades del sector público para hacer frente al covid-19 justificará la necesidad de actuar de manera inmediata, siendo de aplicación el artículo 120 de la Ley 9/2017. 
Se entiende el porqué de esta cláusula: se trata de potenciar la seguridad jurídica de los diversos órganos de contratación, en la medida en que no necesitan acreditar que la contratación de bienes y servicios para hacer frente a la pandemia puede calificarse como emergente.

Pero, junto a la seguridad y simplificación de la motivación, esta cláusula comporta un cierto peligro. Se trata de una previsión en sí misma innecesaria: basta con lo dispuesto en el artículo 120 de la Ley 9/2017 para saber que en situaciones de emergencia se puede utilizar la contratación homónima. Al incluir una cláusula general legitimadora, está estableciendo una presunción iuris et de iure de que, si se trata de hacer frente al covid-19, la contratación es emergente, cuando podría no ser así - por ejemplo, en los casos de contratación de prestaciones complementarias de las señaladas más arriba, enmarcadas en la lucha contra el covid-19, urgentes pero sin carácter inmediato, como suministros a medio plazo de determinados medicamentos, servicios de mantenimiento de respiradores, etcétera-. Se corre así el peligro de eliminar controles previos de determinados contratos que no se justifican en una necesidad perentoria e inmediata, aunque tengan relación con la pandemia. Esta amplísima habilitación podría, además, ser contraria al sentido excepcional de la contratación emergente, al propio artículo 120.2 y a la normativa comunitaria, que exigen una interpretación restrictiva de este privilegio (véase supra).

Con esto está evitando la obligación de motivación: basta señalar que se pretende contratar bienes o servicios que tengan relación con el covid-19 para que se entienda ya justificado el contrato, aunque no sean en sí mismos imprescindibles de inmediato. Será, en todo caso, el órgano de contratación el que deberá valorar la opción entre el acogimiento a los privilegios de la contratación emergente o la utilización de la vía urgente o la ordinaria, en su caso.

\subsection{El ámbito de aplicación de la contratación emergente en la crisis del covid-ı9}

\subsection{I. Ámbito de aplicación temporal}

El ámbito temporal de aplicación de la regulación contenida en los reales decretos leyes depende, por lógica, de la vigencia del propio decreto Ley, que debe ser convalidado o derogado por el Congreso en el plazo de treinta días, o tramitado como ley por el procedimiento de urgencia (artículo 86 Constitución).

Según la disposición transitoria única del Real Decreto Ley 7/2020, del 12 de marzo, "Por el que se adoptan medidas urgentes para responder al impacto económico del covid-19", su regulación facilitadora de la contratación emergente es aplicable también a las tramitaciones de contratos iniciadas con anterioridad al Real Decreto Ley. 
De esta forma, contratos iniciados por la vía procedimental ordinaria o urgente antes de la crisis del covid-19 podrían prescindir desde la entrada en vigor del Decreto Ley, del correspondiente procedimiento administrativo preparatorio, para pasar directamente a la adjudicación. Esta aplicación inmediata (falsa retroactividad) tiene su razón de ser en una constatación: semanas antes de la declaración del estado de alarma (14 de marzo) se sabía de esta epidemia y se fueron adoptando algunas medidas dirigidas al aprovisionamiento de bienes ad hoc sin una especial prisa, porque pocos pensaban que el virus se contagiaría con esa rapidez y extensión, de forma que cuando se aprobó el Real Decreto Ley (12 de marzo) había en curso algunos contratos cuya agilización resultó imprescindible.

\subsection{2. Ámbito de aplicación subjetivo}

En la versión inicial las ventajas de la contratación emergente en relación con el covid-19 solo se refería al sector público estatal ${ }^{17}$, pero tras el Real Decreto Ley 9/2020, del 27 de marzo, "Por el que se adoptan medidas complementarias, en el ámbito laboral, para paliar los efectos derivados del covid-19", se amplía a todo el sector público. Se trata de una modificación lógica, porque todas las administraciones territoriales - y en específico, las comunidades autónomas - tienen competencias vinculadas en mayor o menor medida a la lucha contra el covid-19.

En el caso de las comunidades autónomas, han mantenido el protagonismo en la prestación de servicios sanitarios y en la consecuente contratación de suministros. De hecho, el decreto de alarma (Real Decreto 463/2020, del14 de marzo, "Por el que se declara el estado de alarma para la gestión de la situación de crisis sanitaria ocasionada por el covid-19") en ningún momento centraliza la contratación pública sanitaria (véanse sus artículos 12 y 13).

Por otra parte, también los entes locales pueden aplicar la contratación de emergencia en el ámbito de sus competencias ${ }^{18}$. Aunque carezcan de competencias sanitarias

17 El sector público está constituido, además de por las administraciones territoriales (Estado, comunidades autónomas, entes locales), por los organismos públicos y entidades de derecho público vinculados o dependientes de las Administraciones Públicas, por las entidades de derecho privado vinculadas o dependientes de las Administraciones Públicas y por las universidades públicas (artículo 2.2 de la Ley 40/20I5, del I de octubre, de Régimen Jurídico del Sector Público).

18 No hay que olvidar que la Ley $7 /{ }_{19}{ }^{5}$, del 2 de abril, Reguladora de las Bases del Régimen Local, contiene una habilitación genérica al alcalde para la actuación ante situaciones de emergencia: "El alcalde es el presidente de la Corporación y ostenta las siguientes atribuciones: m) Adoptar personalmente, y bajo su responsabilidad, en caso de catástrofe o de infortunios públicos o grave riesgo de los mismos, las medidas necesarias y adecuadas dando cuenta inmediata al Pleno" (artículo 20.I). 
sensu stricto, hay, sin embargo, materias en las que las corporaciones locales pueden celebrar contratos enmarcados en la lucha contra el covid-19. Por ejemplo, la gestión de residencias de ancianos de su titularidad y la desinfección y limpieza preventiva de espacios públicos, entre otros.

Pero el Real Decreto Ley 9/2020 amplía las posibilidades de contratación de emergencia a todo el sector público, no solo a las Administraciones territoriales, siempre que las compras estén justificadas por el covid-19.

\subsection{3. Ámbito de aplicación territorial}

La regulación de los contratos en el extranjero se recoge en la disposición adicional primera de la Ley $9 / 2017$. Se trata de una disposición ajena a la contratación de emergencia, que hace referencia a los contratos que "se formalicen y ejecuten en el extranjero". Sin embargo, se ha visto afectada por las disposiciones del estado de alarma porque, en la crisis del covid-19, una buena parte de la contratación inicial - y posterior - tuvo que hacerse en el extranjero - específicamente, en China-, ya que fueron necesarias compras masivas y urgentes de algunos productos - fundamentalmente, guantes y mascarillas-que solo el gigante asiático estaba en condiciones de producir en esas cantidades y con esa premura.

La regulación incluida por el Real Decreto Ley 7/2020 se configura como una regulación excepcional, que no modifica con carácter general las previsiones de la Ley 9/2017, sino que las adecua a la situación generada por el covid-19 de manera exclusiva ${ }^{19}$, porque suponen una específica adaptación a las peculiaridades de las compras en China. Por eso, hay que entender que subsiste la regulación general y normal contenida en la disposición adicional primera de la Ley, sin perjuicio de la aplicabilidad del artículo 16.4 del Real Decreto 7/2020 a las "adquisiciones covid-19".

En cualquier caso, las previsiones de la contratación en el extranjero, introducidas por el artículo 16.4 se aplican única y exclusivamente a la Administración estatal, aunque podrían haberse extendido también a otros entes del sector público con necesidades de compra en el extranjero derivadas del covid-19, en particular las comunidades autónomas. No se acaba de entender bien por qué no se extiende esta previsión al resto del sector público, cuando las demás normas de contratación covid-19 sí lo hacen. También dichos procesos autonómicos o locales de compra de imperiosa urgencia podrían agilizarse con la regla del pago del precio total anticipado y de un régimen de garantías más flexible.

19 Ximena Lazo Vitoria, "Contratación pública de emergencia covid-rg”, Observatorio de Contratación Pública, 3I de marzo de 2020, http:/www.obcp.es/opiniones/contratacion-publica-de-emergencia-covid-rg. 
Las novedades del artículo 16.4 del Real Decreto 7/2020 en este punto son:

Cambio competencial para la formalización de los contratos: No hay excepciones. En primer lugar, se produce un cambio competencial para la formalización de los contratos. La disposición adicional primera atribuye la competencia para formalizar la contratación en el extranjero de la Administración estatal al "jefe de misión o representación permanente" dependiente del Ministerio de Asuntos Exteriores y de Cooperación. Solo se exceptúan de estas reglas al Ministerio de Defensa y los organismos autónomos, entidades gestoras y servicios comunes de la Seguridad Social.

En contraste, la norma aprobada señala que

la formalización de los contratos corresponderá al jefe de la misión o representación permanente [nótese que no se establece la adscripción], con sujeción a las condiciones libremente pactadas por la Administración con el contratista extranjero, cuando la intervención de este sea absolutamente indispensable para la ejecución del contrato, por requerirlo así la atención de las necesidades derivadas de la protección de las personas y otras medidas adoptadas por el Consejo de Ministros para hacer frente al covid-19, y así se acredite en el expediente. No obstante, esta competencia podrá avocarse por el titular del departamento ministerial competente por razón de la materia.

Aunque la redacción del precepto no es muy clara, parece que su intención es concentrar en un solo órgano la competencia para la formalización de la contratación en el extranjero, incluyendo las excepciones antes referidas (el Ministerio de Defensa y Seguridad Social).

Expresa habilitación para pagar el precio de manera anticipada. Una segunda modificación y de mayor envergadura es la habilitación expresa y amplia para pagar el precio de forma anticipada. El artículo 16.4, párrafo tercero de la Ley establece que

podrán realizarse la totalidad o parte de los pagos con anterioridad a la realización de la prestación por el contratista, en la forma prevista en el apartado 2.

Hay que recordar que esta posibilidad (pago anticipado) ya se consagra de forma explícita en la Ley para la contratación en el extranjero (disposición adicional primera, letra g). Bien es cierto que al hablar de "anticipo" parece aludir solo a un pago parcial, pero el Real Decreto 7/2020 va más allá, introduciendo una mayor flexibilización, al posibilitar el pago anticipado total.

No solo eso: mientras que la disposición adicional primera condiciona el anticipo a que se constituya una garantía ("se deberá exigir garantía que cubra el anticipo"), el Real Decreto 7/2020 rebaja esta obligatoriedad, trasladando al órgano de contratación las decisiones 
en torno a ella. Este es el sentido de la remisión "en la forma prevista en el apartado 2", cuyo contenido ya hemos comentado. Es cierto que la citada disposición ya considera la posibilidad - excepcional en todo caso- de eximir la garantía por anticipo, pero la regulación del Real Decreto es mucho más amplia en supuestos y también en las potestades que atribuye al órgano de contratación.

El riesgo de quebranto lo asumen los presupuestos generales del Estado. Debe destacarse que las previsiones anteriores (contratación en el extranjero covid-19) se acompañan de una regla de enorme envergadura:

El riesgo de quebranto que pudiera derivarse de estas operaciones será asumido por el presupuesto del Estado.

Se trata de no perjudicar a los intermediarios o a los bancos que intervienen o facilitan las transacciones, de forma que este tipo de operaciones - ciertamente riesgosas - no les disuada y se termine retrasando la ejecución de la prestación que tiene carácter de extrema urgencia. Estamos, en definitiva, ante un "seguro de quebranto" que asume en cualquier caso el Estado para suprimir riesgos económicos de los sujetos intervinientes en las operaciones de compra.

\subsection{4. Ámbito de aplicación objetivo}

Aunque la normativa específica sobre contratos en la crisis del covid-19 no lo menciona, el normador contempla sobre todo los contratos de suministros. No tiene ningún sentido -no estaría justificada - la aplicación de las ventajas de la contratación de emergencia a las concesiones de servicios u obras públicas, que son contratos de tracto sucesivo y no dirigidos, por tanto, a la satisfacción de necesidades puntuales. Por la peculiaridad de la catástrofe vírica cabría, en algún caso, la contratación de obras de emergencia (hospitales u otros) o la prestación de determinados servicios de emergencia de carácter médico. Pero en lo fundamental la contratación emergente en este periodo se refiere a suministros: desinfectantes, mascarillas, respiradores, medicinas, equipos de protección individual (EPI), etcétera. Ello se aprecia en específico en la regulación de los contratos de emergencia en el extranjero y de los modos de pago.

\subsection{Sustitución del control previo de gastos por la intervención del Estado por el control financiero permanente}

Esta no es una norma contractual, sino un criterio general de aplicación de los controles relativos a los gastos públicos, sin valor normativo.

Mediante la Resolución del 23 de marzo de 2020, de la Intervención General de la Administración del Estado, por la que se publica el Acuerdo del Consejo de Ministros del 17 de 
marzo de 2020, "Por el que se adoptan medidas urgentes y excepcionales en el ámbito del control de la gestión económico-financiera efectuado por la intervención general de la Administración del Estado como consecuencia del covid-19”, se prevé la aplicación preferente del control financiero permanente sobre el control previo de gastos hechos por la intervención del Estado. En efecto, la citada resolución establece en su acuerdo primero:

Hasta que el normal funcionamiento de los servicios sea restablecido, podrá aplicarse el régimen de control financiero permanente en sustitución de la función interventora.

Como puede apreciarse, no se trata de una disposición de naturaleza normativa, sino de un criterio interpretativo, que permite inaplicar de manera provisional una potestad previa de control de gasto, manteniendo otras ${ }^{20}$; se trata - dentro del marco legal de la Ley General Presupuestaria- de evitar que el control de la intervención pueda retrasar la ejecución de gastos vinculados a compras de emergencia. Por eso, se deja a juicio de la Administración la supresión temporal del control previo, en función de sus concretas necesidades de provisión de bienes.

\subsection{Las garantías de la prestación en los casos de abono a cuenta: De la obligación legal a la discrecionalidad administrativa}

Como establece la Ley 9/2017, cuando en un contrato público la Administración debe hacer abonos a cuenta antes de la ejecución de la prestación, está obligada a exigir garantías. En efecto, según su artículo 198.3,

el contratista tendrá derecho a percibir abonos a cuenta por el importe de las operaciones preparatorias de la ejecución del contrato y que estén comprendidas en el objeto del mismo, en las condiciones señaladas en los respectivos pliegos, debiéndose asegurar los referidos pagos mediante la prestación de garantía.

Pues bien, el artículo 16.2 del Real Decreto de Ley 7/2020 —-modificado en este punto por el Real Decreto de Ley 8/2020, del 17 de marzo - relaja las condiciones de constitución de la garantía:

20 El control financiero permanente se define en el artículo I57 de la Ley 47/2003, del 26 de noviembre, General Presupuestaria: "El control financiero permanente se ejercerá en los órganos y entidades establecidos en el artículo siguiente y tendrá por objeto la verificación de una forma continua realizada a través de la correspondiente intervención delegada, de la situación y el funcionamiento de las entidades del sector público estatal en el aspecto económico-financiero, para comprobar el cumplimiento de la normativa y directrices que les rigen y, en general, que su gestión se ajusta a los principios de buena gestión financiera y en particular al cumplimiento del objetivo de estabilidad presupuestaria y de equilibrio financiero". 
En estos casos, si fuera necesario realizar abonos a cuenta por actuaciones preparatorias a realizar por el contratista, no será de aplicación lo dispuesto respecto a las garantías en la mencionada Ley 9/2017, siendo el órgano de contratación quien determinará tal circunstancia en función de la naturaleza de la prestación a contratar y la posibilidad de satisfacer la necesidad por otras vías. De la justificación de la decisión adoptada deberá dejarse constancia en el expediente.

Por tanto, cuando el artículo 16.2 declara inaplicable lo "dispuesto respecto a las garantías en la mencionada Ley 9/2017”, se está refiriendo a las garantías que el artículo 198.3 de la Ley exige para garantizar los pagos a cuenta. Se flexibiliza la constitución de garantías, puesto que no es aplicable a estos efectos la regulación de la Ley, y se permite al órgano de contratación que, en función de las circunstancias, elija otras vías para asegurar el cumplimiento por parte del contratista.

En definitiva, el órgano de contratación deberá, en función de las circunstancias y de forma creativa, determinar si conviene o no, en cada caso concreto, establecer garantías si se producen pagos anticipados por actuaciones preparatorias; $y$, en caso positivo, disponer una garantía adecuada a esa prestación.

Otra vez nos encontramos con una técnica de flexibilización de la contratación, que puede suponer, en el caso concreto, un riesgo de que se irroguen perjuicios a la Administración contratante, pero que, en el balance entre beneficios y desventajas, merece la pena aplicarlo para facilitar las prestaciones inmediatas.

Por tanto, será el órgano de contratación el que determine la garantía aplicable en función de la naturaleza de la prestación a contratar - por ejemplo, con un nivel rebajado de exigencias por las normas presupuestarias-o incluso establecer otros medios distintos de garantía. Aunque la norma no lo dice con rotundidad, entiendo que también cabe la no exigencia de garantía ${ }^{21}$. En suma, la norma suspende la obligación de prestar garantía ex artículo 198.3 de la Ley 9/2017 (contratación covid-19), trasladando la decisión acerca de su exigibilidad y forma de prestación al órgano de contratación.

\section{CONCLUSIÓN}

La contratación de emergencia se apoya en dos tipos de disposiciones: la regulación general, plasmada en la Ley 9/2017 (artículos 120 y concordantes), abierta a una pluralidad de situaciones posibles, y la regulación excepcional, dictada ad hoc (en este caso, con motivo de la crisis del covid-19); la segunda viene a completar - o derogar ad casum-a la primera. Sendos tipos de disposiciones apuntan a una reducción de trámites procedi-

21 De acuerdo con lo señalado por Lazo Vitoria, "Contratación...”. 
mentales y de controles económicos y de legalidad previos a la contratación para facilitar la recepción inmediata de la prestación necesaria, y a la flexibilización de otras técnicas de control de la ejecución.

En todos estos casos, por tanto, la inmediatez de la prestación prima sobre la seguridad jurídica, por lo que los riesgos de incumplimiento o de abuso de la posición del proveedor son mucho mayores en la contratación de emergencia que en la contratación ordinaria; sin embargo, el legislador prefiere facilitar la inmediata satisfacción de las necesidades de la Administración, aunque eso suponga mayores riesgos.

En cualquier caso, aunque se reducen los controles previos a la adjudicación y a la ejecución, se mantienen otros controles instrumentales posteriores, como el importantísimo de la publicación de la adjudicación y, lógicamente, los de legalidad judicial, tanto en vía contencioso-administrativa como en vía penal. 


\section{BIBLIOGRAFÍA}

- Álvarez García, Vicente. El concepto de necesidad en derecho público. Madrid: Civitas, 1996.

- Baca Oneto, Víctor Sebastián. La invalidez de los contratos públicos. Madrid: Thomson Reuters Civitas, 2006.

- Gallego Córcoles, Isabel. "Los procedimientos abiertos, restringido, licitación con negociación, negociado sin publicidad y diálogo competitivo". En Estudio sistemático de la ley de contratos del sector público. Dirigido por José María Gimeno Feliú. Madrid: Aranzadi, 2018.

- Gimeno Feliú, José María. "La crisis sanitaria covid-19 y su incidencia en la contratación pública”. El Cronista del Estado Social y Democrático de Derecho 86-87 (2020): 44-53. http://www.elcronista.es/sumario_numero_86-87.asp.

- Martínez López-Muñiz, José Luis. “¿Sociedades públicas para construir y contratar obras públicas?”. Revista de Administración Pública 144 (1997): 45-74. https://dialnet.unirioja.es/servlet/articulo? codigo $=17367$.

- - "Naturaleza de los contratos públicos a la luz del derecho español, su fundamento y sus consecuencias”. En Derecho administrativo: Obra colectiva en homenaje al profesor Miguel S. Marienhoff. Coordinado por Juan Carlos Cassagne. Buenos Aires: Abeledo-Perrot, 1998.

- Santamaría Pastor, Juan Alfonso. Principios de derecho administrativo II. 5. ${ }^{\mathrm{a}}$ ed. Madrid: Iustel, 2018.

- Sanz Rubiales, Íñigo. "La protección del ambiente en la nueva Ley de Contratos: Del Estado meramente 'comprador' al Estado 'ordenador”. Revista de Administración Pública 205 (2018): 49-80. https://dialnet. unirioja.es/servlet/articulo?codigo $=6386334.1$ 